\title{
On the right track
}

\author{
Recent progress demonstrates the potential of hydrogen as a vector for decarbonization in different sectors of the \\ energy system, but continued support is required to avoid losing momentum in delivering solutions to climate and \\ energy goals.
}

\begin{abstract}
n September 2018, the world's first hydrogen fuel cell-powered trains entered service on a route in northern Germany ${ }^{1}$. Previously, the $100 \mathrm{~km}$ non-electrified route was served by diesel engines. Key in the decision to employ hydrogen power here was the desire to clean-up the network, coupled with the difficulty in electrifying this particular line. The scheme indeed plays to the strengths of hydrogen: the train can run for $1,000 \mathrm{~km}$ without
\end{abstract} refuelling - similar to a diesel train - and the fixed point-to-point nature of rail travel removes concerns over limited hydrogen refuelling stations, a frequently expressed downside of hydrogen-powered personal transportation. Plans are afoot to deliver 14 more hydrogen trains in the state of Lower Saxony by 2021, while in the United Kingdom there have been suggestions that hydrogen trains could be on tracks as early as 2022 - the motivation there also being to phase-out diesel power without having to electrify lines, which can be costly.

These developments lend weight to the idea that hydrogen could play an important role in energy system decarbonization, not least transport. However, the source of the hydrogen used by such projects is critical to their decarbonization potential; the hydrogen currently powering the trains in Germany is the byproduct of an industrial process, but the operators have committed to support cleaner methods for hydrogen production in the future.

One approach might be to use renewable power to electrolyse water. However, there remains uncertainty as to whether this approach can be cost-competitive with those based on production of hydrogen from fossil fuels. Gunther Glenk and Stefan Reichelstein explore this question in their Article in this issue. They carried out an economic analysis and applied it to scenarios in Germany and Texas; the results suggest that compared with hydrogen produced from fossil sources, hydrogen obtained from wind power is already cost-competitive in niche applications and may become more widely competitive in the foreseeable future.

This gives hope that greener hydrogenproduction methods might become more economically viable with the right kind of support. Indeed, such technology received a boost in February, with the announcement in Germany of plans to build a $100 \mathrm{MW}$ power-to-gas plant producing hydrogen gas by electrolysis ${ }^{2}$. The plant would run on electricity produced by wind turbines in the country's northwest and follows an earlier announcement by different operators about plans to construct a separate $100 \mathrm{MW}$ power-to-gas plant running on offshore wind farms in the North Sea ${ }^{3}$. These projects would demonstrate, at a relatively large scale, coupling of the electricity and gas sectors, with the produced hydrogen being available for use for transport but also for heating and even as a feedstock in industrial chemical processes. Such linkages between sectors may open up other avenues for decarbonization potential beyond just transport and are one of the main strengths of hydrogen as an energy carrier.

Hydrogen can also play a role in providing large-scale and flexible storage for power systems with high degrees of renewables. In their Article in this issue, Chuancheng Duan, Ryan O'Hayre and colleagues report the development of a highly efficient reversible protonic electrochemical cell that allows electricity and hydrogen to be interconverted in a single device. The technology could operate in a similar fashion to a battery whereby hydrogen is produced in the charging period (electrolysis mode) and then converted back into electricity during discharge (fuel-cell mode). This approach may eventually be most useful in the context of grid-scale seasonal storage as the energy storage capacity of the system is limited by the amount of hydrogen that can be stored rather than by a property of the electrochemical device itself. More discussion of this work can be found in the accompanying News \& Views by José Serra.

Hydrogen is indeed already being generated to make use of excess electricity from renewable sources and naturally it isn't only wind energy that can be used for electrolysis to produce clean hydrogen. Last year, Scotland's Orkney Islands became the first place in the world to produce hydrogen using tidal power ${ }^{4}$. The islands were producing more electricity through onshore wind and tidal generation than they could consume so they installed a $0.5 \mathrm{MW}$ electrolyser to produce hydrogen when supply exceeds demand. Compressed hydrogen is then transported to another island in the archipelago and used in a fuel cell to power some harbour operations. A broad consortium of funders and partners is involved, comprising members of local communities, charities, industry, local and national government, and the European Union. There are now plans in Orkney to launch the world's first hydrogen-powered car and passenger sea ferry. Scheduled for 2021 , the ferry would not run purely on hydrogen - rather, the hydrogen would be injected into the air-fuel mixture of the ferry's diesel engine - but would nevertheless improve fuel consumption and cut emissions.

Although the developments in Germany and Scotland represent a tiny fraction of Europe's energy demand, these kinds of projects and trials are vital in demonstrating the viability of hydrogen and providing a testing ground that could inform wider adoption. Hydrogen offers opportunities to cut emissions in hard-to-decarbonize parts of our energy system in ways that can work synergistically with a more renewable power system. While some funding is in place, to realize the full potential of hydrogen, long-term support is necessary both at the lab level and to enable trials of technology that is ready for implementation. For this to happen, governments will need to commit to taking hydrogen more seriously, making more funds available and creating an enabling and supportive environment for businesses to develop.

Published online: 13 March 2019

https://doi.org/10.1038/s41560-019-0366-6

References

1. Germany launches world's first hydrogen-powered train. The Guardian (17 September 2018); https://go.nature.com/2XmFKM5

2. German energy grids say plans ready for $100 \mathrm{MW}$ hydrogen plant. Reuters https://go.nature.com/2TlTZBm (11 February 2019).

3. Gasunie, TenneT and Thyssengas reveal detailed, green 'sector coupling' plans using power-to-gas technology. Tenne $T$ https:// go.nature.com/2tDxr0q (16 October 2018).

4. Orkney's ageing ferries look to ditch diesel for hydrogen. Financial Times (27 December 2018); https://go.nature. com $/ 2$ EdehUe 